ارزيابى اكولوزيك آلودگى آلى خليج گر گان با استفاده از شاخص جلبكى بالمر

\author{
يريسا ملكى'، رحمان يّاتيمار "، حجت الله جعفريان'، عبدالرسول سلمان ماهينى ‘، رسول قربانى"؛ \\ محمد قلىزاده' و محمد هرسيج'
}

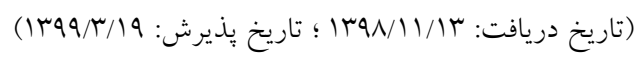

جّكيده

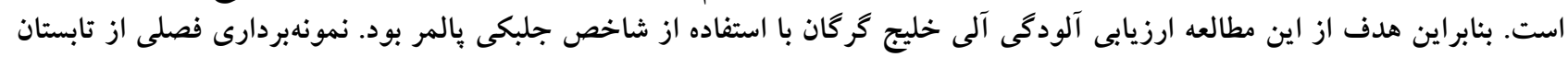

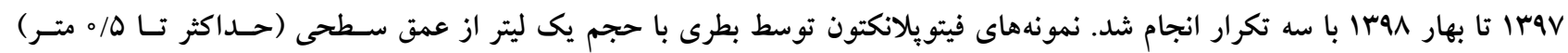

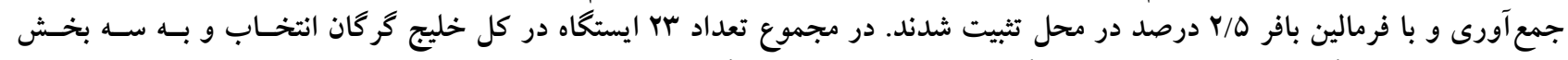

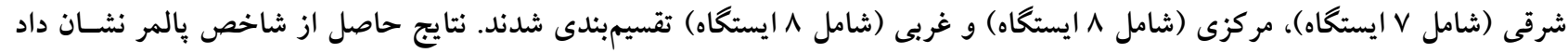

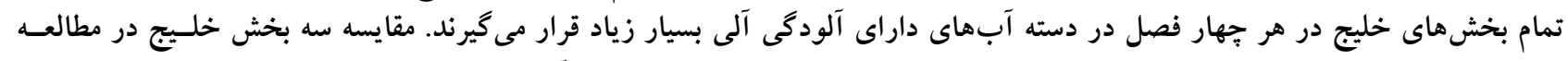

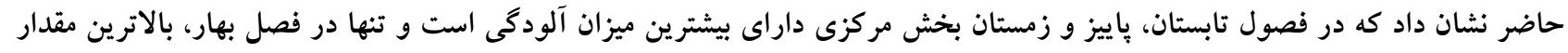

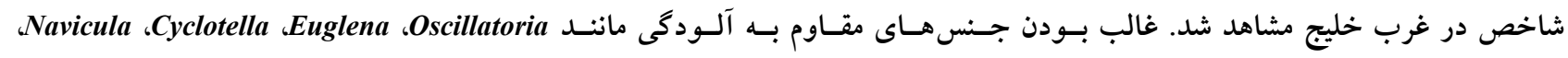
Nitzschia

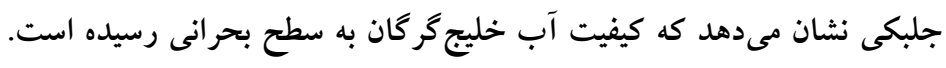

وازههاى كليدى: فيتويلانكتون، شاخص بالمر، خليج گر كان، آلودگى آلى

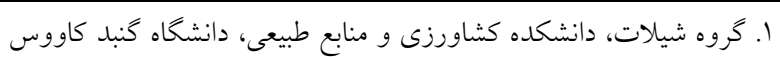

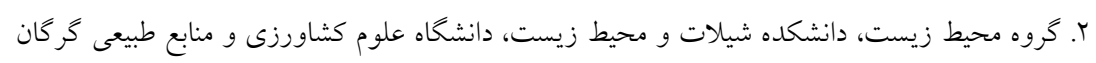

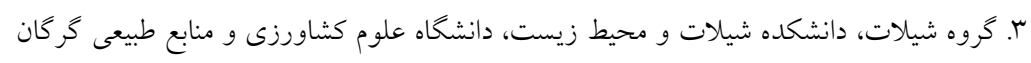

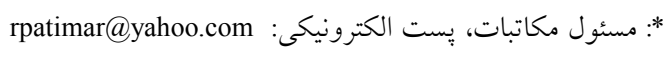


مورد استفاده قرار مى گيرد. سالم و همكـاران (YY)، اوياديـاى و

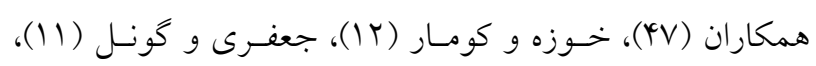

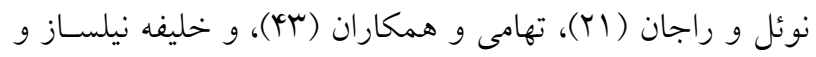

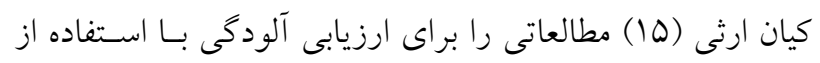

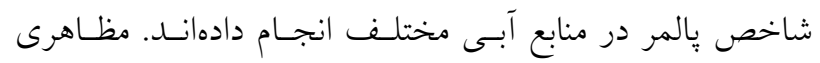
كوهانسـتانى و همكــاران (1) در بخشسى از مطالعاتشــان، از

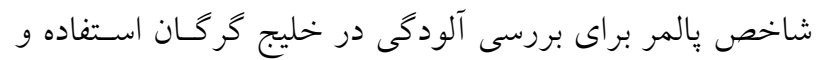

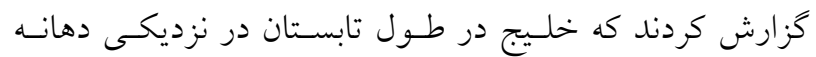

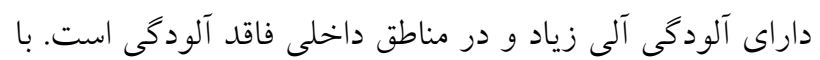

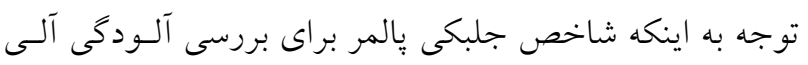

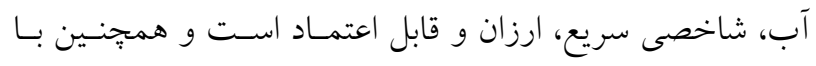

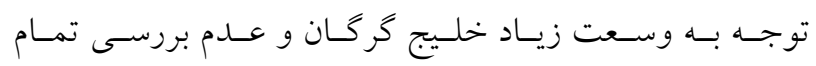

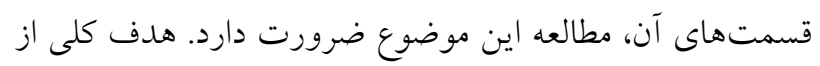

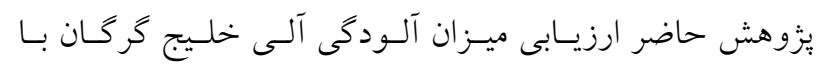

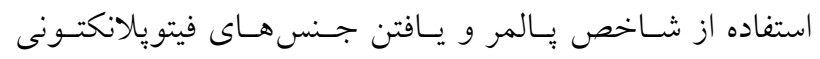
شاخص در مكانهاى آلوده به مواد آلى است.

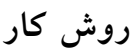

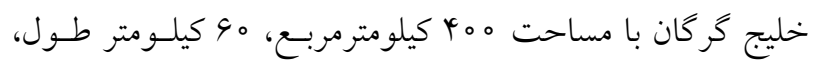

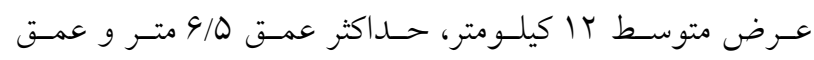
متوسط إه متر در انتهاى جنوبشرقى درياى خزر واقـع شـده

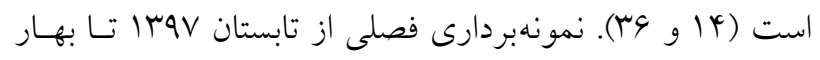

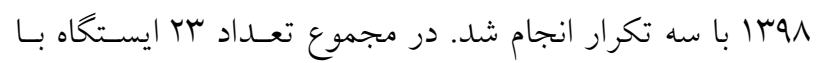

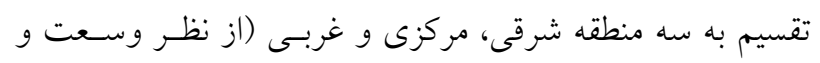

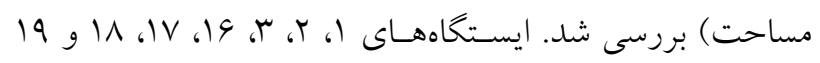

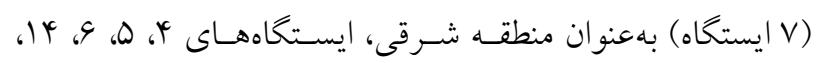

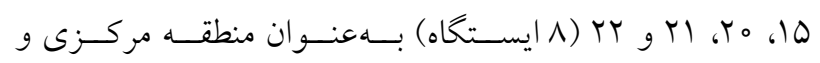

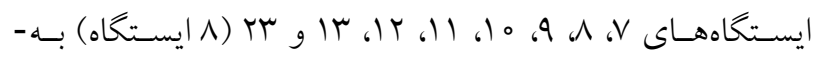

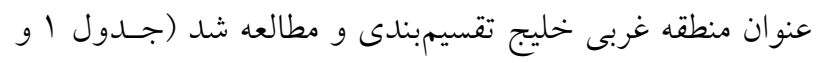

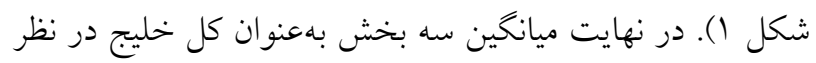

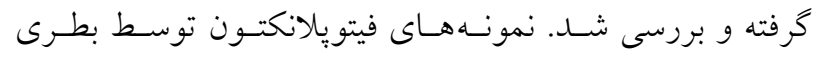

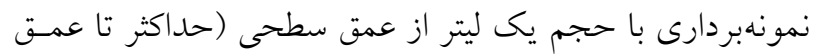

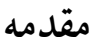

آلودكى آلى ييكرههاى آبى يكى از مهمترين موضوعات كيفيـت

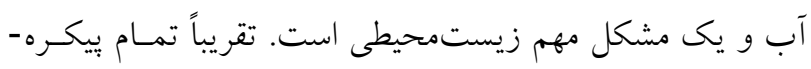

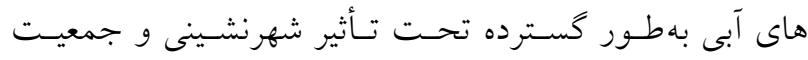

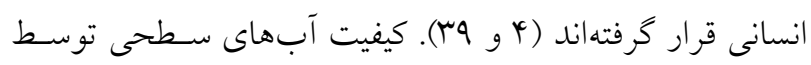

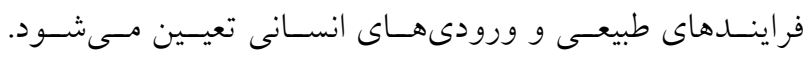

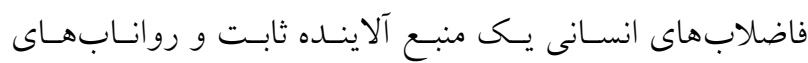

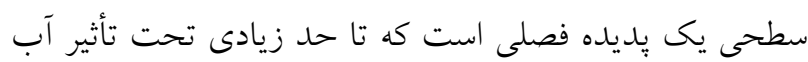

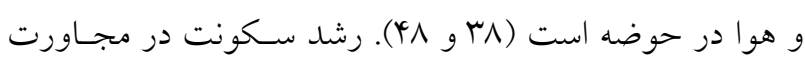

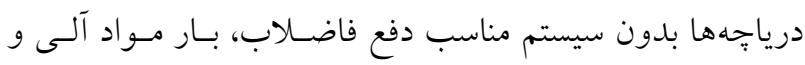

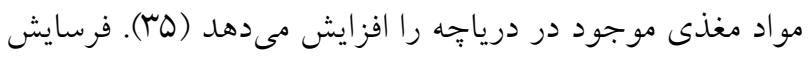

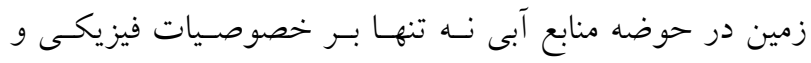

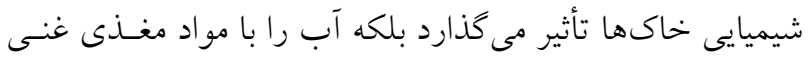

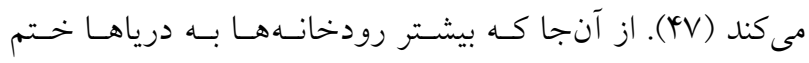

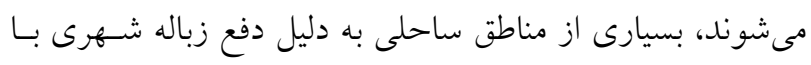

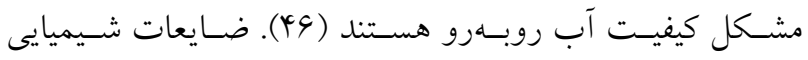
حاصل از فرايندهاى صنعتى كاهى بهطور تصادفى در رودخانسه

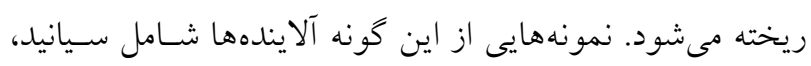

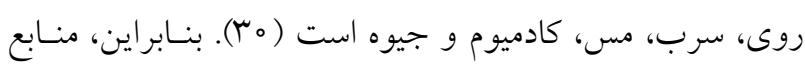

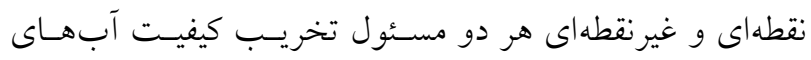

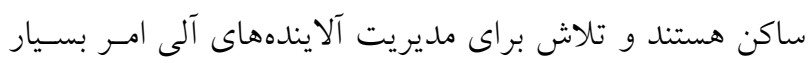

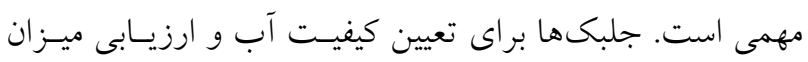

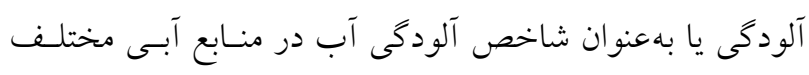

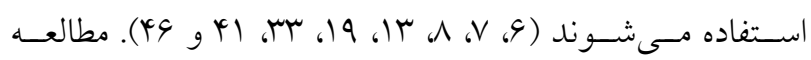

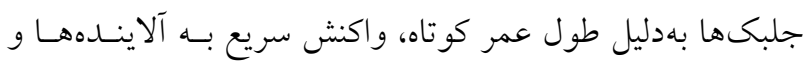

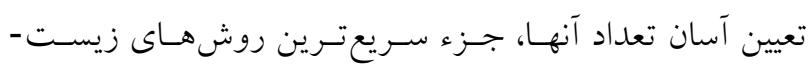
شناختى در بررسى تغيير كيفيت آب بهشمار مىرود (Y). اولـين

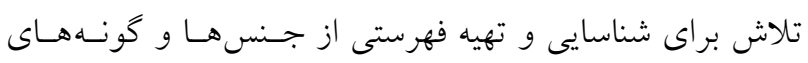

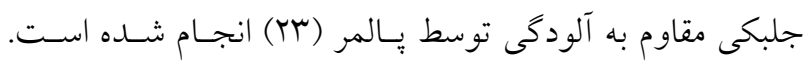
شاخص جلبكى پالمر يكى روش سـريع، قابـل اعتمـاد و نسـبتاً

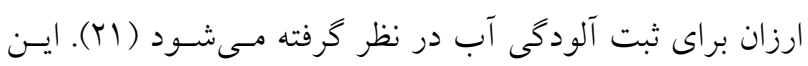
شاخص براى آلودكى غير آلى و ميزان يوتريفيكاسـيون (r) نيـز 


\section{جدول 1. موقعيت جغرافيايى ايستخاههاى نمونهبردارى و تقسيمبندى آنها}

\begin{tabular}{|c|c|c|c|c|c|c|c|c|c|c|c|c|c|c|c|c|c|c|c|c|c|c|c|}
\hline$v_{0}^{3}$ & 1 & $r$ & $r$ & ${ }^{r}$ & 0 & 4 & $v$ & $\wedge$ & 9 & 10 & 11 & Ir & Ir & 14 & 10 & 19 & IV & 11 & 19 & $r_{0}$ & $r$ & Yr & $\pi$ \\
\hline 䨔 & " & : 3 & : & $y^{3}{ }^{3}$ & फ' & $y^{3} y^{3}$ & $\stackrel{y}{y}$ & 3 & $\frac{y}{y}$ & पे & पy & $\sqrt[4]{y}$ & $\frac{y}{y}$ & 異' & $\left.y^{3}\right)^{3}$ & :"3) & "3. & . & "3) & $\hat{y}^{3}$ & 产' & $\hat{y}^{3}$ & $\begin{array}{c}y \\
y\end{array}$ \\
\hline X & $\begin{array}{l}\text { त̃ } \\
0 \\
0 \\
0 \\
\end{array}$ & 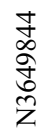 & 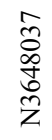 & $\begin{array}{l}n \\
\tilde{n} \\
\hat{\sigma} \\
\tilde{c} \\
z\end{array}$ & \begin{tabular}{l}
$\bar{\sigma}$ \\
\multirow{0}{0}{} \\
$\tilde{z}$
\end{tabular} & 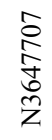 & 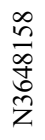 & 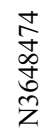 & 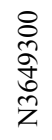 & 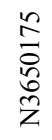 & 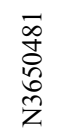 & $\begin{array}{l}\widetilde{\sigma} \\
\stackrel{\bar{Z}}{0} \\
\check{z}\end{array}$ & 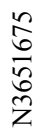 & $\begin{array}{l}\frac{J}{2} \\
\text { ర్ } \\
\tilde{Z}\end{array}$ & $\begin{array}{l}\hat{\circ} \\
\text { ర్ర } \\
\text { ż }\end{array}$ & 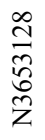 & $\begin{array}{l}\text { ò } \\
\hat{\overbrace{}} \\
\hat{\delta} \\
\tilde{c}\end{array}$ & 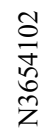 & 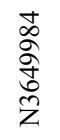 & $\begin{array}{l}\stackrel{0}{0} \\
\stackrel{0}{0} \\
\check{z}\end{array}$ & 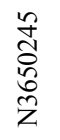 & 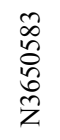 & $\begin{array}{l}\hat{\tilde{n}} \\
0.0 \\
\tilde{n} \\
z\end{array}$ \\
\hline $\mathrm{Y}$ & 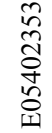 & 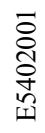 & $\begin{array}{l}\bar{\infty} \\
\hat{n} \\
\tilde{n} \\
n\end{array}$ & 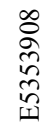 & $\begin{array}{l}\text { do } \\
\text { के } \\
\tilde{n} \\
\text { In }\end{array}$ & 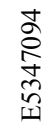 & 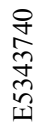 & 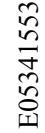 & 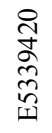 & 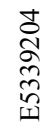 & 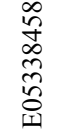 & 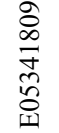 & 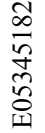 & 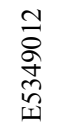 & 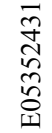 & 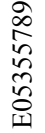 & 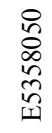 & 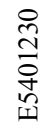 & 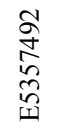 & 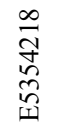 & 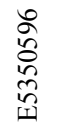 & 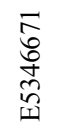 & 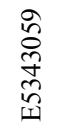 \\
\hline
\end{tabular}

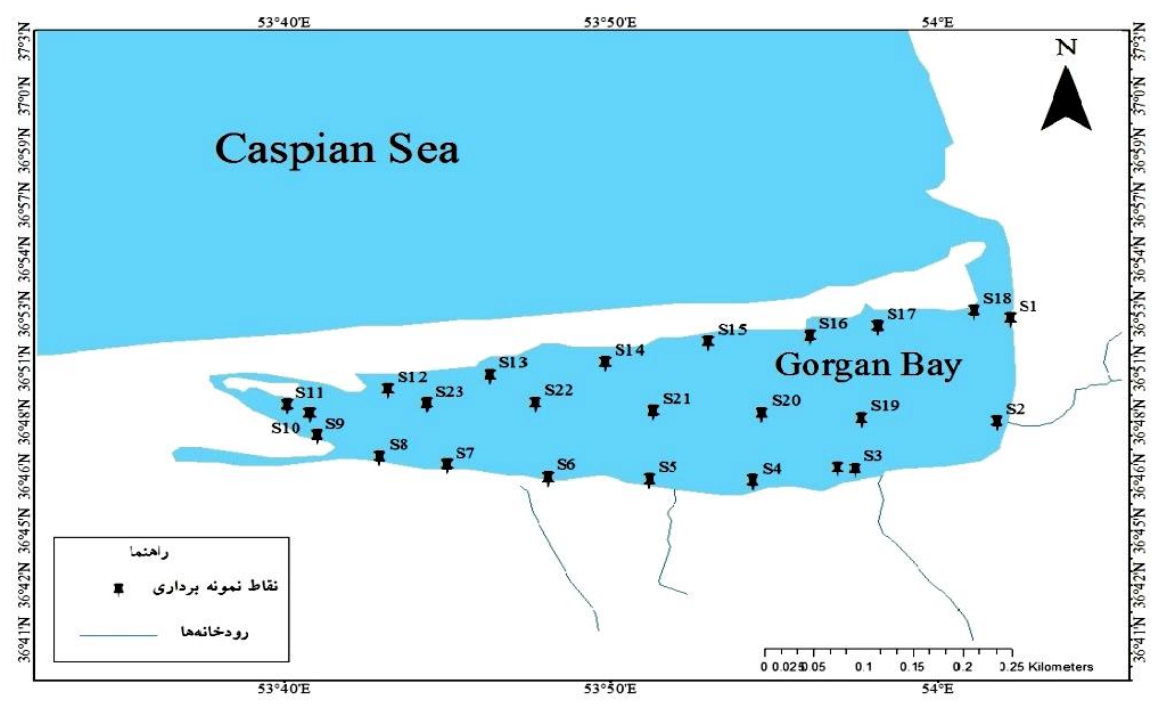

شكل 1. تصوير موقعيت نقاط نمونه بردارى (رنخى در نسخه الكترونيكى)

ضريب مخصوص داده شد (جدول Y) و در نهايت اين ضرايب

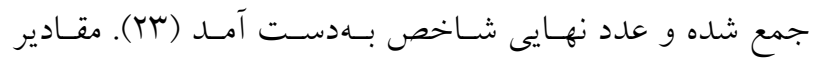

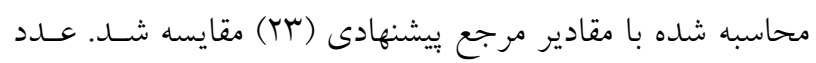

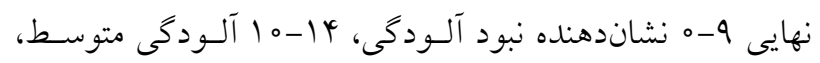

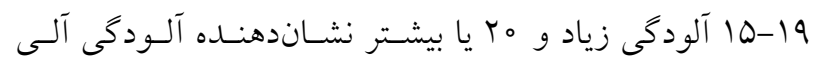
بسيار زياد است.

\section{نتايج}

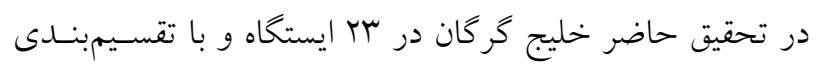

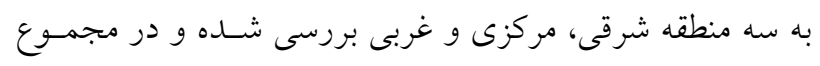

0/0 متر) تهيه شدند. نمونهها يس از جمع آورى در هر ايستـاه،

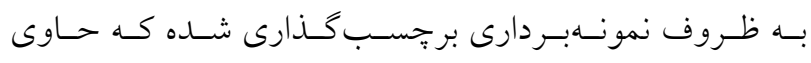

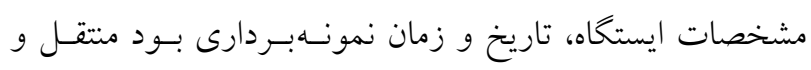

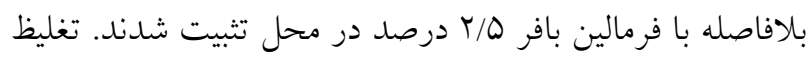

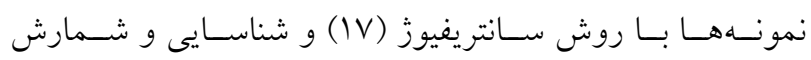

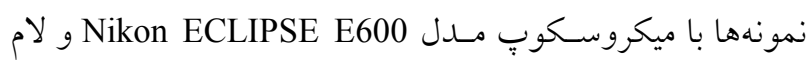

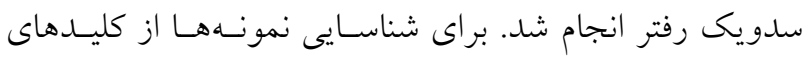

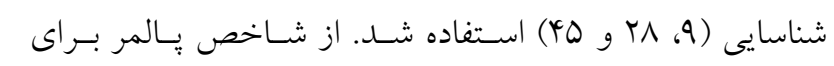

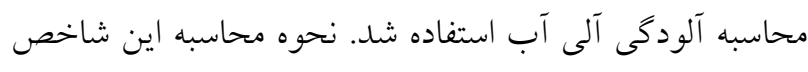

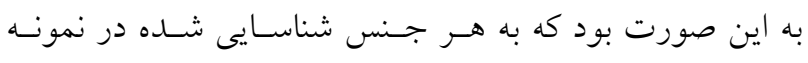




\begin{tabular}{|c|c|c|c|c|c|c|c|}
\hline جنس & ضريب & جنس & ضريب & جنس & ضريب & جنس & ضريب \\
\hline Anacystis & 1 & Micractinium & 1 & Cyclotella & 1 & Phacus & r \\
\hline Ankistrodesmus & r & Navicula & r & Euglena & 0 & Phormidium & 1 \\
\hline Chyamydomonas & 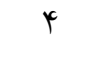 & Nitzschia & r & Gomphonema & 1 & Scenedesmus & $r$ \\
\hline Chlorella & r & Oscillatoria & 0 & Lepocincils & 1 & Stigoclonium & r \\
\hline Closterium & 1 & Pandorina & 1 & Melosira & 1 & Synedra & r \\
\hline
\end{tabular}

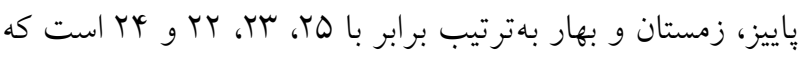

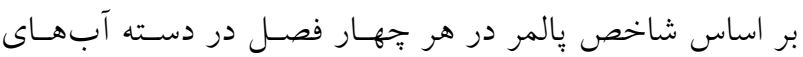

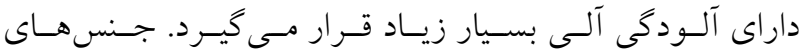
،Cyclotella ،Ankistrodesmus ،Euglena ،Oscillatoria Nitzschia Navicula بخش مشاهده شدند (جدول ه و نمودار r).

\section{منطقه غربى خليج گر گان}

در مجموع Y T جنس فيتويلانكتونى در اين منطقه مشاهده شد كـه تعداد ها جنس جزء جنس هاى شاخص آلـودگى يـالمر هسـتند. ميزان شاخص در اين منطقه بـراى جهـار فصـل تابسـتان، يـاييز،

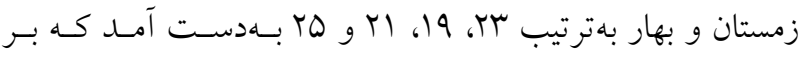
اساس دستهبندى شاخص پالمر در فصلهاى تابسـتان، زمسـتان و بهار در دسته آبهاى داراى آلودگى آلى بسـيار زيـاد و در فصـل

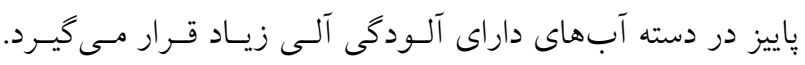

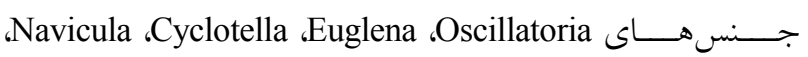
Nitzschia

$$
\text { شدند (جدول } 9 \text { و نمودار r). }
$$

\section{كل خليج گر گان}

در اين منطقه در مجموع \& Y جنس فيتويلانكتونى مشـاهده شـد كه تعداد ال جنس جـزء جــس هــاى شـاخص آلـودگى يـالمر هستند. اعداد بهدست آمله از شاخص در اين منطقه براى تجهـار

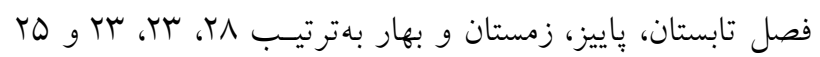
است كه بر اساس دستهبندى شاخص پيالمر در هر جهـار فصـل در دسته آبهاى داراى آلودگى آلى بسيار زياد قرار مى گيرند.

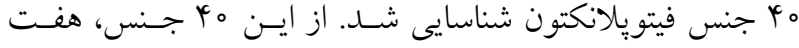

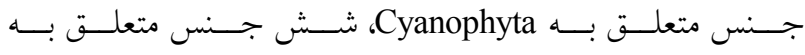
Chlorophyta متعلق به Pyrrhophyta، دو جنس متعلق بـه Euglenophyta و 11 جنس متعلق به Bacillariophyta است. در مجموع |ل جنس كـه

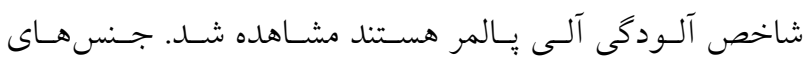
و Nitzschia Navicula ،Cyclotella ‘Euglena ، Oscillatoria دynedra مشاهده شده در خليج در جهار فصـل تابستان، يـاييز و زمسـتان

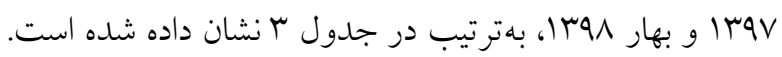

\section{منطقه شرقى خليج گر گان}

در مجموع rV جنس فيتويلانكتونى در اين منطقه مشـاهده شــ كه تعداد 1ل جنس جـزء جــس هــاى شـاخص آلـودگى يـالمر بودند. ميزان شاخص در اين منطقه براى جهـار فصـل تابسـتان،

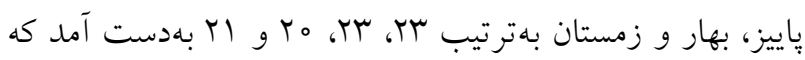
بر اساس دستهبندى شاخص پِالمر، در هر جّهار فصل در دسـه

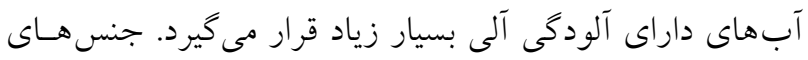
و Nitzschia NNavicula ،Cyclotella ،Euglena ،Oscillatoria در هـر جهــار فصـل در ايسن بخـش مشــاهده شــند Synedra

$$
\text { (جدول أبو نمودار (). }
$$

\section{منطقه مركزى خليج گر گان}

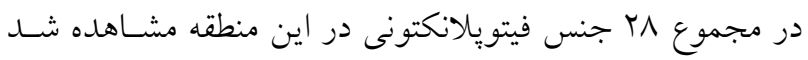

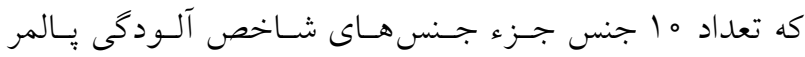
هستند. ميزان شاخص در اين منطقه براى فصـل هــاى تابسـتان، 


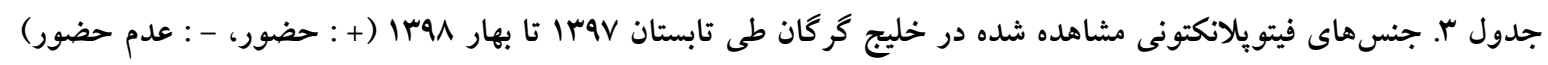

\begin{tabular}{|c|c|c|c|c|c|c|c|c|c|c|c|c|c|c|c|c|c|c|}
\hline \multicolumn{4}{|c|}{ 1 } & \multicolumn{4}{|c|}{ 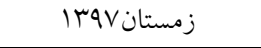 } & \multicolumn{4}{|c|}{ 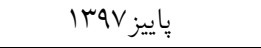 } & \multicolumn{4}{|c|}{ تابستان IrqV } & \multirow[b]{2}{*}{ 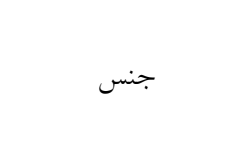 } & \multirow[b]{2}{*}{ شاخه } & \multirow[b]{2}{*}{ ر بر } \\
\hline 马 & 3 & $\begin{array}{l}3 \\
y^{3}\end{array}$ & $\frac{y}{y}$ & b & $=3$ & $y^{3}$ & $\frac{y}{y}$ & ๖ & 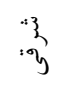 & $\hat{y}^{3}$ & $\frac{4}{3}$ & ๖ & $\begin{array}{l}* 3 \\
: y\end{array}$ & $\begin{array}{l}3 \\
y^{3} \\
y^{2}\end{array}$ & $\frac{4}{3}$ & & & \\
\hline+ & + & + & + & + & + & + & + & + & + & + & + & + & + & + & + & Oscillatoria & & 1 \\
\hline- & - & - & - & + & - & + & - & - & - & - & - & + & - & + & - & Lyngbya & & r \\
\hline+ & + & + & + & + & + & + & + & + & + & + & + & + & + & + & + & Anabaena & & $r$ \\
\hline+ & + & + & + & - & - & - & - & + & + & + & - & + & + & + & + & Cylindrospermopsis & Cyanophyta & $r$ \\
\hline+ & + & - & + & + & + & + & + & + & + & + & - & + & + & + & + & Spirulina & & Q \\
\hline+ & + & - & - & - & - & - & - & - & - & - & - & + & - & + & - & Merismopedia & & 9 \\
\hline+ & - & - & + & - & + & + & - & + & + & + & + & + & + & + & + & Chroococcus & & v \\
\hline+ & + & + & + & + & - & + & + & + & + & + & - & + & + & + & + & Ankistrodesmus & & $\wedge$ \\
\hline+ & + & + & + & - & - & - & - & - & - & - & - & + & + & + & + & Kirchneriella & & 9 \\
\hline+ & + & + & + & + & + & + & + & + & + & + & + & + & + & + & + & Schroederia & & 10 \\
\hline+ & - & + & + & + & - & + & + & - & - & - & - & - & - & - & - & Planctonema & Chlorophyta & 11 \\
\hline+ & - & + & + & - & - & - & - & - & - & - & - & + & - & + & - & Chlorella & & ir \\
\hline- & - & - & - & + & - & + & - & - & - & - & - & + & + & + & - & Closterium & & 14 \\
\hline- & - & - & - & - & - & - & - & - & - & - & - & + & + & - & - & Coelastrum & & 14 \\
\hline- & - & - & - & + & - & + & - & - & - & - & - & - & - & - & - & Spirogyra & Charophyta & 10 \\
\hline+ & + & + & + & + & + & + & + & + & + & + & + & + & + & + & + & Exuviaella & & 19 \\
\hline+ & + & + & + & + & + & + & + & + & + & + & + & + & + & + & + & Prorocentrum & & IV \\
\hline+ & + & + & + & + & + & + & + & + & + & + & + & + & + & + & + & Gymnodinium & Pyrrhophyta & 11 \\
\hline+ & + & + & - & - & - & - & - & - & - & - & - & + & + & + & + & Peridinium & & 19 \\
\hline+ & - & - & + & + & + & + & - & + & + & + & - & + & + & + & - & Gonyaulax & & ro \\
\hline+ & + & + & + & + & + & + & + & + & + & + & + & + & + & + & + & Euglena & Fuglenonhyta & Yl \\
\hline- & - & - & - & - & - & - & - & + & + & + & - & + & - & - & + & Phacus & Euglenopnyta & rt \\
\hline+ & + & + & + & + & + & - & + & + & + & + & + & + & + & + & + & Cocconies & & $r^{\mu}$ \\
\hline+ & - & + & + & + & + & - & + & + & + & + & - & - & - & - & - & Coscinodiscus & & ry \\
\hline+ & + & + & + & + & + & + & + & + & + & + & + & + & + & + & + & Cyclotella & & TQ \\
\hline+ & + & + & + & + & + & + & + & + & + & + & + & + & + & + & + & Cymbella & & rq \\
\hline+ & - & + & - & - & - & - & - & + & + & + & - & + & + & + & + & Diatoma & & TV \\
\hline+ & + & + & + & + & + & + & + & + & + & + & + & + & + & + & + & Gyrosigma & & $r \wedge$ \\
\hline+ & - & - & + & + & + & - & - & - & - & - & - & + & + & - & - & Melosira & & rq \\
\hline+ & + & + & + & + & + & + & + & + & + & + & + & + & + & + & + & Navicula & & $r_{0}$ \\
\hline+ & + & + & + & + & + & + & + & + & + & + & + & + & + & + & + & Nitzschia & Bacillarionhyta & rl \\
\hline- & - & - & - & - & - & - & - & + & + & + & - & + & - & + & + & Rhizosolenia & Bacillariophyta & rt \\
\hline- & - & - & - & - & - & - & - & + & - & + & - & + & - & - & + & Surirella & & r \\
\hline+ & + & + & + & + & + & + & + & + & + & + & + & + & + & + & + & Synedra & & ry \\
\hline+ & - & + & - & - & - & - & - & - & - & - & - & - & - & - & - & Thalassiosira & & ro \\
\hline+ & - & + & - & + & - & + & - & + & + & + & + & + & + & - & - & Cymatopleura & & re \\
\hline+ & - & + & - & - & - & - & + & - & - & - & - & - & - & - & - & Amphiprora & & rv \\
\hline- & - & - & - & + & - & + & - & + & + & + & + & + & - & + & - & Rhoicosphenia & & rی \\
\hline- & - & - & - & + & - & - & + & + & + & + & - & - & - & - & - & Amphora & & ra \\
\hline- & - & - & - & - & - & - & - & + & + & + & - & - & - & - & - & Stauroneis & & $\varphi_{0}$ \\
\hline$\Gamma_{0}$ & $r_{0}$ & rQ & YY & TQ & $r_{0}$ & $\overline{r \mu}$ & $T_{0}$ & 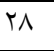 & TV & $r \wedge$ & IV & $m$ & TY & 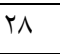 & TY & مجموع جنس ها & & \\
\hline
\end{tabular}


جدول ؟ب. جنسهاى شاخص بالمر مشاهده شده در بخش شرقى خليج گر كان

\begin{tabular}{|c|c|c|c|c|c|c|}
\hline بهار & زمستان & باييز & تابستان & ضريب يالمر & جنس & \\
\hline 0 & 0 & 0 & 0 & 0 & Oscillatoria & 1 \\
\hline r & - & r & r & r & Ankistrodesmus & r \\
\hline- & - & - & - & $r$ & Chlorella & $r$ \\
\hline- & - & - & 1 & 1 & Closterium & r \\
\hline 0 & 0 & Q & 0 & 0 & Euglena & 0 \\
\hline- & - & r & - & r & Phacus & 9 \\
\hline 1 & 1 & 1 & 1 & 1 & Cyclotella & v \\
\hline- & 1 & - & 1 & 1 & Melosira & $\wedge$ \\
\hline$r$ & r & $r$ & $r$ & $r$ & Navicula & 9 \\
\hline$r$ & $r$ & $r$ & $r$ & $r$ & Nitzschia & 10 \\
\hline r & r & r & r & r & Synedra & 11 \\
\hline rI & ro & r & r & & & \\
\hline
\end{tabular}

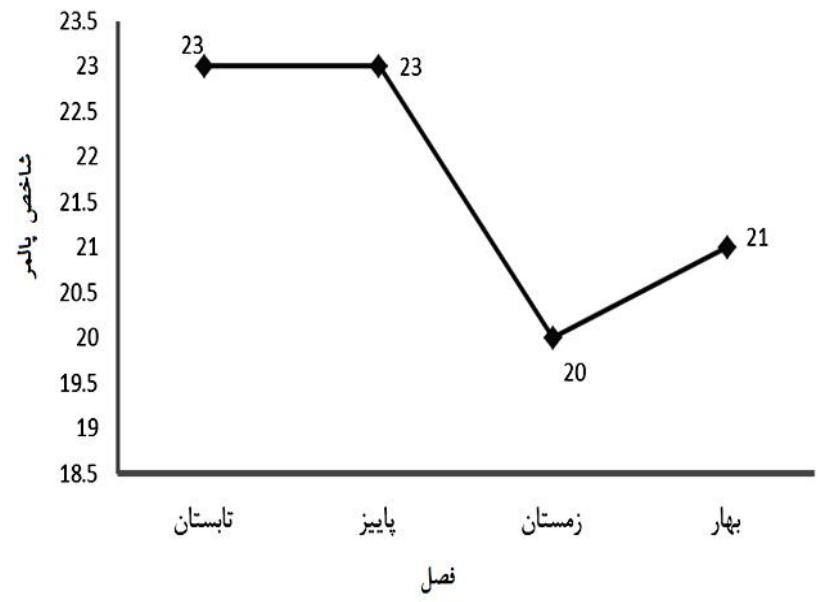

نمودار ا. شاخص بالمر در بخش شرقى خليج گر گان

جدول ه. جنسهاى شاخص يالمر مشاهده شده در بخش مركزى خليج گر گان

\begin{tabular}{|c|c|c|c|c|c|c|}
\hline بهار & زمستان & بإييز & تابستان & ضريب يالمر & جنس |جن & \\
\hline 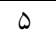 & 0 & 0 & 0 & 0 & Oscillatoria & 1 \\
\hline r & r & r & r & r & Ankistrodesmus & r \\
\hline r & - & - & r & $r$ & Chlorella & $r$ \\
\hline - & 1 & - & 1 & 1 & Closterium & r \\
\hline 0 & 0 & 0 & 0 & 0 & Euglena & 0 \\
\hline- & - & r & - & r & Phacus & 4 \\
\hline 1 & 1 & 1 & 1 & 1 & Cyclotella & v \\
\hline r & r & r & r & r & Navicula & $\wedge$ \\
\hline r & r & $r$ & r & r & Nitzschia & 9 \\
\hline r & r & r & r & r & Synedra & 10 \\
\hline ry & rr & $r$ & ro & & & \\
\hline
\end{tabular}




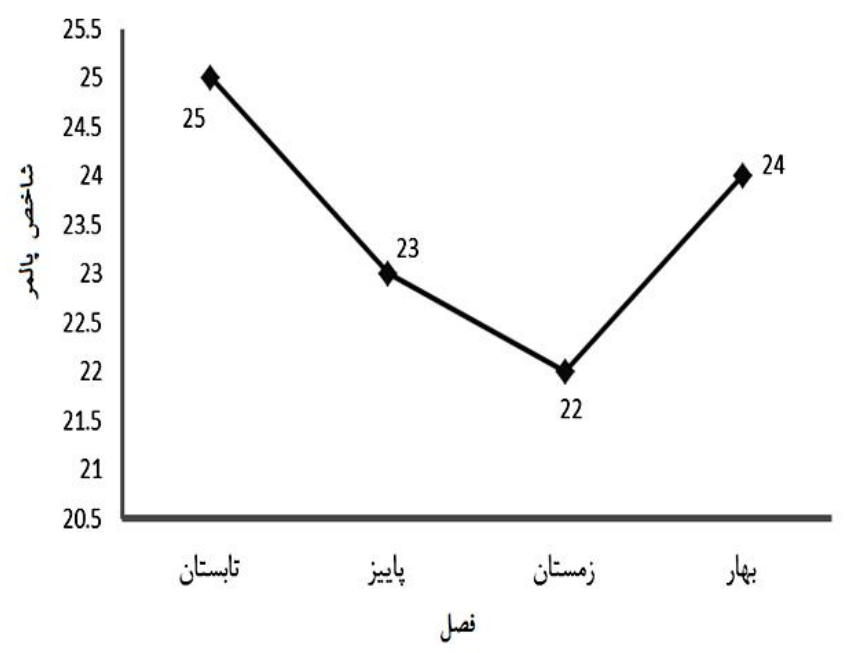

نمودار r. شاخص پيالمر در بخش مركزى خليج گركان

\begin{tabular}{|c|c|c|c|c|c|c|}
\hline بهار & ز مستان & 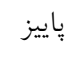 & ت ت ت ابستان & ضريب پِالمر & 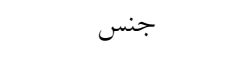 & \\
\hline 0 & 0 & 0 & 0 & 0 & Oscillatoria & 1 \\
\hline r & r & - & r & r & Ankistrodesmus & r \\
\hline r & - & - & - & r & Chlorella & $r$ \\
\hline 0 & 0 & 0 & 0 & 0 & Euglena & r \\
\hline- & - & - & r & r & Phacus & 0 \\
\hline 1 & 1 & 1 & 1 & 1 & Cyclotella & 9 \\
\hline 1 & - & - & - & 1 & Melosira & v \\
\hline r & r & r & r & r & Navicula & $\wedge$ \\
\hline r & r & r & r & r & Nitzschia & 9 \\
\hline$r$ & r & r & r & r & Synedra & 10 \\
\hline ro & r) & 19 & r & & & \\
\hline
\end{tabular}

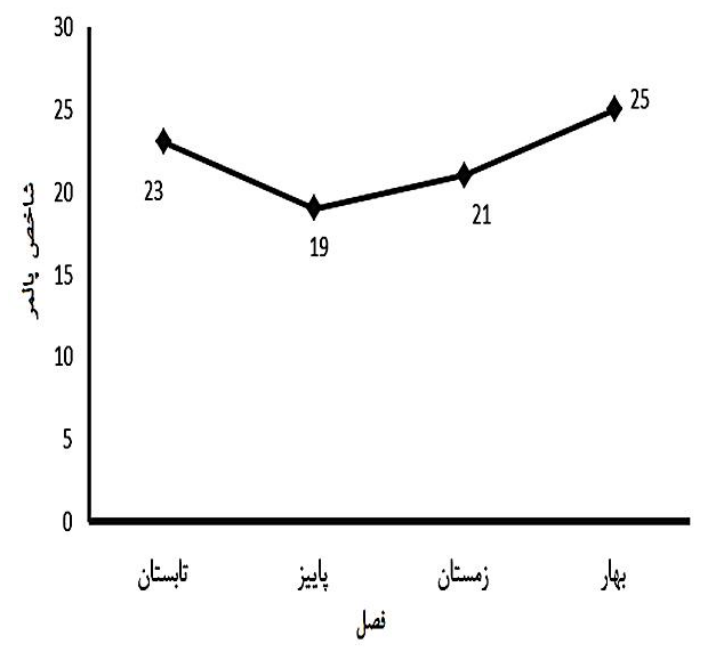

نمودار r. شاخص بالمر در بخش غربى خليج گر گان 


\begin{tabular}{|c|c|c|c|c|c|c|}
\hline بهار & زمستان & بإييز & ت ت ت ابستان & ضريب بالمر & جنس & \\
\hline 0 & 0 & $\Delta$ & $\Delta$ & 0 & Oscillatoria & 1 \\
\hline r & r & r & r & r & Ankistrodesmus & r \\
\hline r & - & - & $r$ & $r$ & Chlorella & r \\
\hline- & 1 & - & 1 & 1 & Closterium & $r$ \\
\hline 0 & 0 & 0 & 0 & 0 & Euglena & 0 \\
\hline- & - & r & r & r & Phacus & 9 \\
\hline 1 & 1 & 1 & 1 & 1 & Cyclotella & v \\
\hline 1 & 1 & - & 1 & 1 & Melosira & $\wedge$ \\
\hline r & r & r & r & $r$ & Navicula & 9 \\
\hline r & $r$ & $r$ & $r$ & $r$ & Nitzschia & 10 \\
\hline r & r & r & r & r & Synedra & 11 \\
\hline TQ & r & r & rی & & & \\
\hline
\end{tabular}

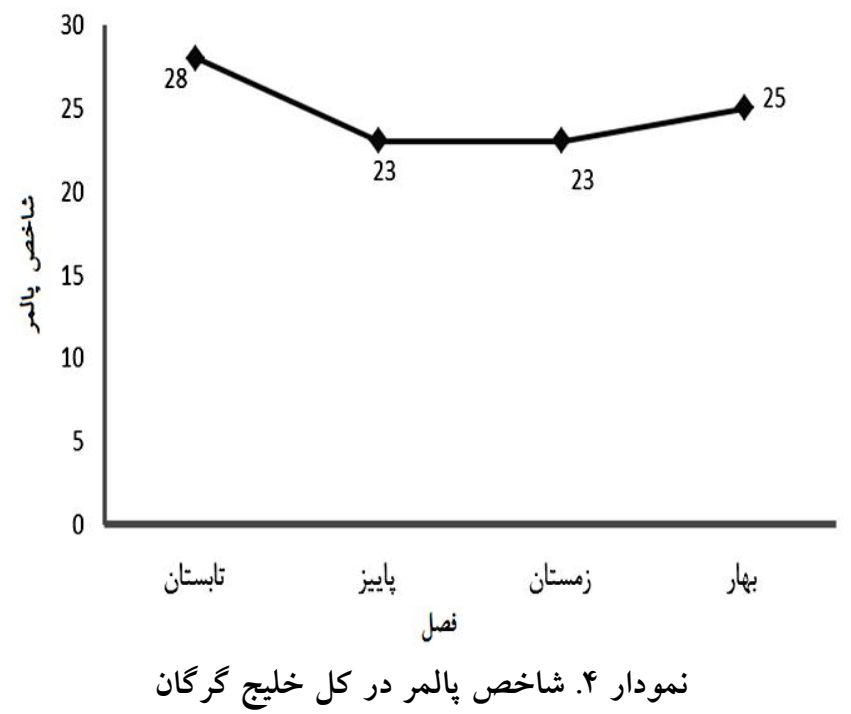

است و دو بخش ديخر داراى مقدار كمتر با عدد سז هسـتند. در فصل ياييز بخش مركزى و شرقى با عدد با آلودهتـــ از بخـش غربى با عدد 19 است. در فصل زمستان بالاترين ميزان شاخص در مركز با علد ب T است و بخششهاى غربى و شرقى بـهنتيـبـ مقدار آ و ه r را نشان دادند. در بهار بالاترين مقـدار شـاخص در غرب خليج با عدد ها ديده شد و كمترين ميـزان در بـخـش شرقى با عدد الب بهدست آمد. در نهايت بر اساس اعداد بهدست آمله شاخص بِالمر مىتوان بخش هاى مختلف خليج گرگـان در

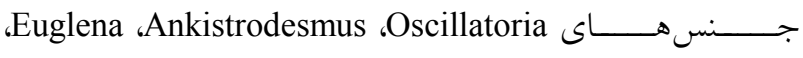
Synedra Nitzschia ،Navicula ،Cyclotella فصل در اين بخش مشاهده شدند (جدول V و نمودار \&). خلاصه اعداد شاخص بِالمر در بخش هـاى مختلـف خلـيج كر گان در جدول (N) و ميانخين شـاخص بـالمر در طـى جهـار فصل براى بخششهاى مختلـف در نمـودار هار ارئسه شـده اسـت. مقايسه سه بخش خليج در مطالعه حاضر نشان داد كه در فصـل

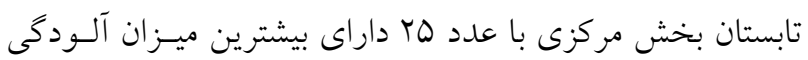


ارزيابى اكولوزيك آلودگى آلى خليج كر كان با استفاده از...

جدول 1. جنس هاى شاخص بالمر مشاهده شده در خليج كر كان

$$
\text { بإلمر بهار }
$$

بإلمر زمستان

بإلمر باييز

بإلمر تابستان

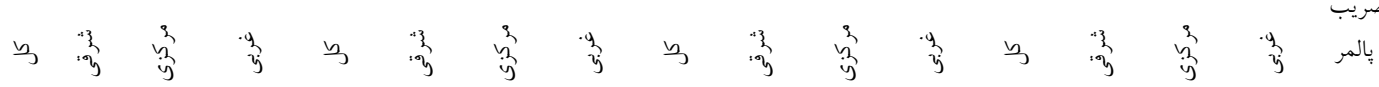

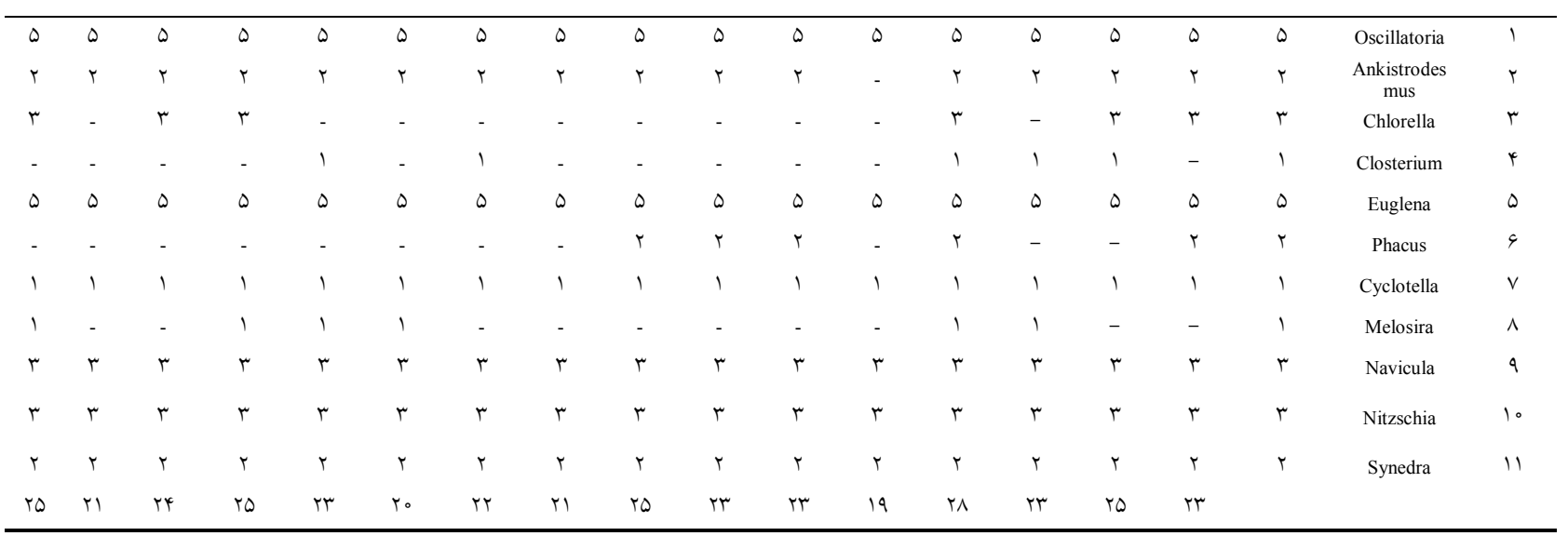

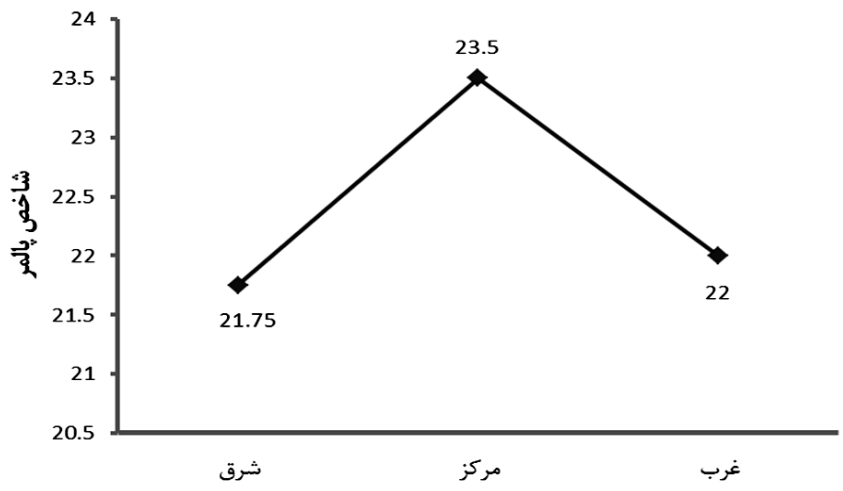

نمودار هـ مقايسه ميانگين جهار فصل شاخص بالمر براى سه بخش خليج گركان

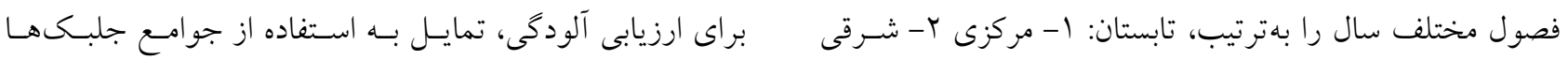

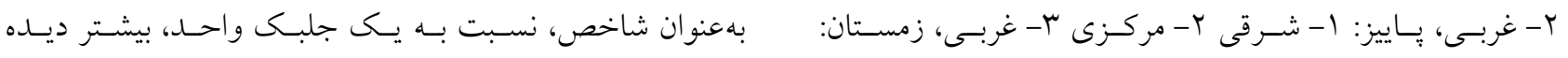

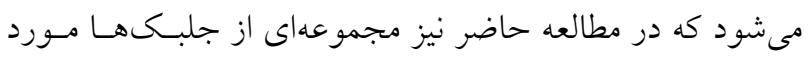
ا- مركزى

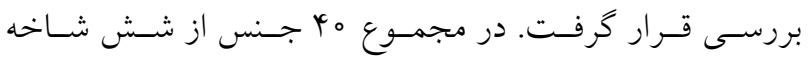
r- شرقى طبقهبندى كرد (نمودارهاى ( تا ها ). ‘Pyrrhophyta ،Charophyta ،Chlorophyta ،Cyanophyta ت Euglenophyta

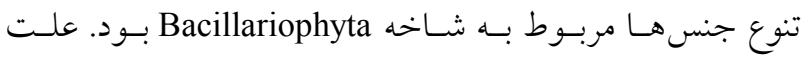

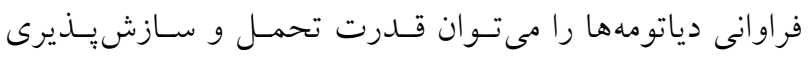

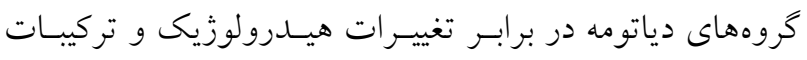

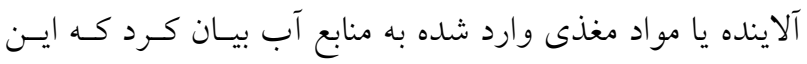

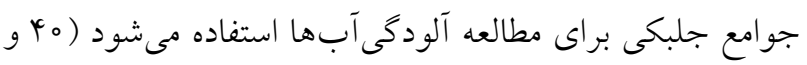

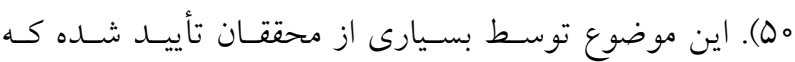

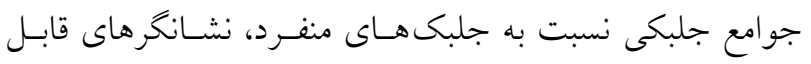

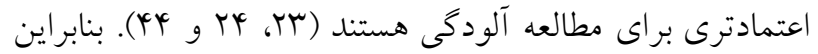

or 
كلــى مشــخص كنتـــه وجـــود ســطح تغذيــهاى بيشــرفته و اوتريفيكاسيون است (ب (M). حضور ير تراكم اين جنس مىتوانسد بهدليل ورود فاضلابها و روانابها به محيط باشد كـه نيازمنـد اقدامات اصلاحى است.

\section{منطقه مركزى خليج گر كان}

منطقه مركزى خليج گر گان بر اساس شـاخص يـالمر در فصـل تابستان نشاندهنده ميزان آلودخى آلى زياد است كه با مطالعـات مظاهرى و همكاران (1) مغايرت دارد. ايشان خـزارش كردنـــ خليج در بخش داخلى فاقد آلودگى است. همجنين ايسن منطقـه در فصول ديخر سال نيز داراى عدد شـاخص بـالايى بـود و در

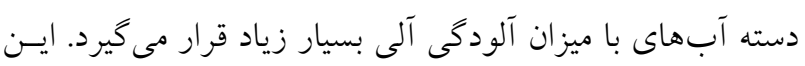
امر مىتواند بهدليـل حضـور مسـتمر جــس هــاى Oscillatoria، ،Navicula ‘Cyclotella ‘Ankistrodesmus ‘Euglena Nitzschia شده است. همجنينين حضور جـنس Chlorella از جلبـكهـاى سـبز در فصل تابستان و بهار با ضريب يالمر بالا، مىتواند بهدليل وجـود مواد مغذى زياد و آلودكى باشد كه موافـق نظـر عبدالحامــ (1)

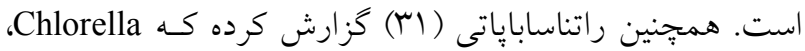
Euglena ،scillatoria شدت آلوده ساكن هستند. بسيارى از تحقيقـات نشـان داده كـه جلبك Chlorella در جداسازى مواد مغذى از زهكش ها بسيار مؤثر اسـت و امسروزه از آن بـراى كـاهش بــار مــواد مغـــى در سيستمهاى آبى اسـتفاده مسىشـود. جـنس Phacus نيـز در ايسن منطقه در فصل باييز مشـاهده شـد كـه بـا مشـاهدات رابـرت و و همكاران (rr) و حسمانى و بهاراتى (0 ا) شباهت دارد.

\section{منطقه غربى خليج گر گان}

بر اساس شاخص پِالمر، منطقه غربسى خلـيج گرگـان در فصـل

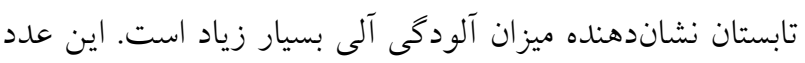
در فصل باييز كاهش بيدا كرده و نشاندهنده آبهاى با آلودگى
موضوع مطابق با يافتههاى ساليوان (YY) و نيبـاكين (YY) اسـت. نيز در تمام طول سال با تراكم زياد در اين منطقه Pyrrhophyta حضور داشتند.

\section{منطقه شرقى خليج گر كان}

منطقه شرقى خليج گر گان بر اسـاس شـاخص يـالمر در فصـل

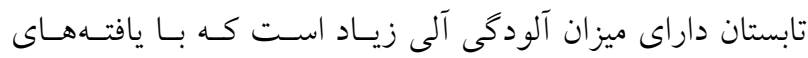
محققان ديخر ساز گار است، از جمله مظاهرى و همكـاران (1) كه ميزان آلودگى خليج در منطقه دهانه آن را در فصـل تابسـتان

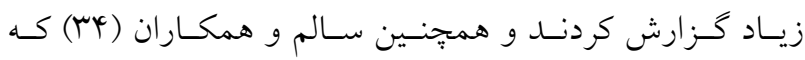
دريافتند دلتاى نيل آلودگى بيشـترى را در طـول تابسـتان نشـان مى دهل

ميزان آلودگى آلى در سه فصل يـاييز، زمسـتان و بهـار بسـيار زياد است كه اين يافته با نتايج مظاهرى و همكاران (1/) مغايرت دارد. ايشان كزارش كردند اين بتخـش از خلـيج در فصـول ديخــ داراى آلودگى نيست. اين مغايرت مىتواند بهدليـل عمـق زيـاد و حضور جنس هاى مقاوم به سطح آلودگى آلى بالا مثـل Euglena، Nitzschia ،Navicula ،Cyclotella بخش بـا يافتسههـاى بلينخــر و سـيكى (r) مطابقـت دارد كـه. جـس هــاى Cyclotella، Mynedra ،Nitzschia ،Melosiera ، Chlorella ، Oscillatoria شناسايى شده در مطالعاتشان كزارش كردند. دو جــس Euglena و Oscillatoria جنس هايیى با قابليت تحمل آلـودگى بسـيار زيـاد هستند كه در تمام فصول در اين بخش مشاهده شــند. ايـن امـر مى تواند دليل بالا بودن مقدار شاخص در اين منطقه باشـد كـه بـاــا كزارش باتريك (YY) مطابقت دارد. جنس Euglena در فصل تابستان بـه وفـور در خلسيج ديـده شد. بِالمر (TM)، رابرت و همكاران (TM) و حسمانى و بهـاراتى

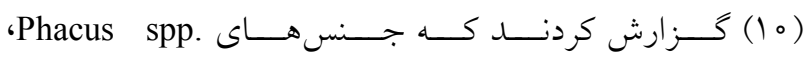
Lepocinclis spp. و Chlamydomonas spp. ‘Euglena spp. بهويزه در فصل تابستان ميزان آلودگى آلى زياد را نشان مىدهند كه نتيجه اين مطالعه را تأييد مى كند. Euglenophyceae بهطـور 


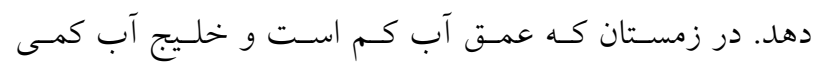

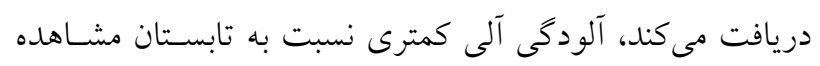

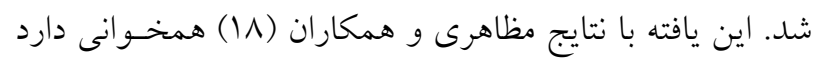

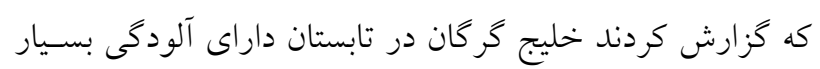
زيادى بوده و مناطق نزديك دهانسه آن در وضـعيت آلـوده قـرار دارند. - مان. جلبكهاى سـبز آبى جــس Oscillatoria در تمـام خلـيج و همجنِين دياتومه جنس Melosira در بيشتر مناطق مشاهده شــــ

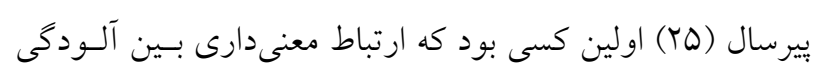

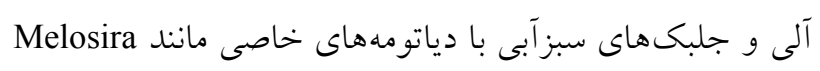

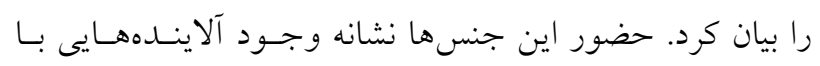

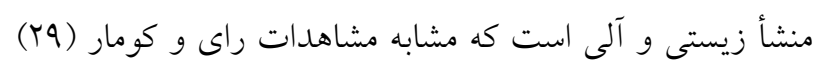
و كاست و همكاران (ه) است.

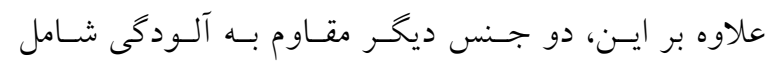
Navicula Euglena

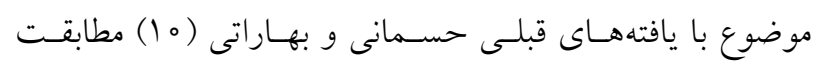

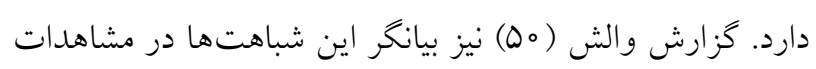
آنها بوده و ارتباط اين جلبكها با آلودكى آلى را تأييد مى كند.

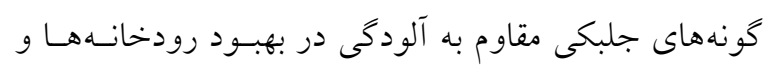

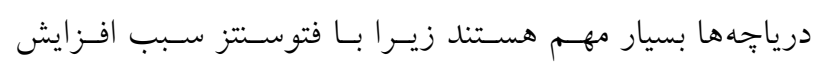

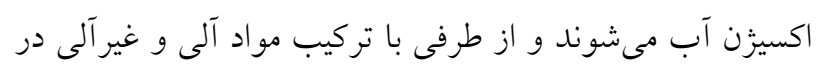

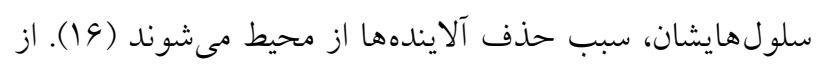

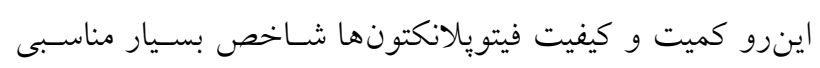

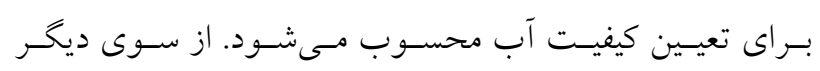

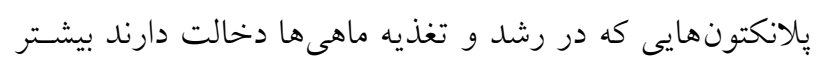

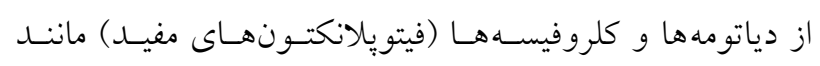
،Closterium ،Navicula ، Nitzschia Ankistrodesmus و هستند كه در اين مطالعه حضـور Synedra

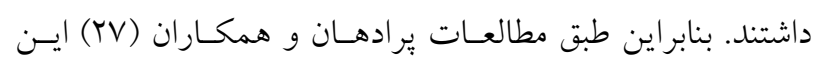

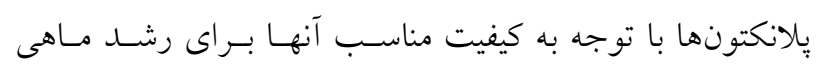

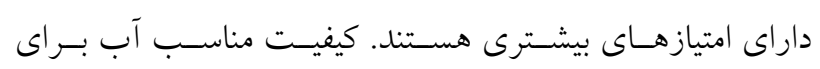

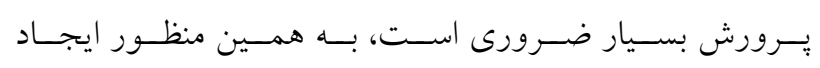

بالا است. ميزان اين شاخص دوباره در فصـل زمسـتان افـزايش

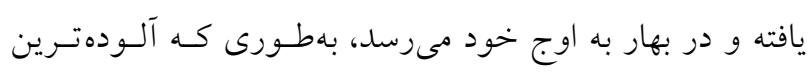

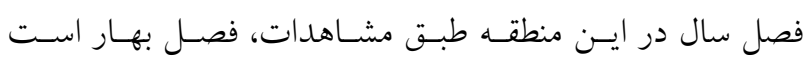

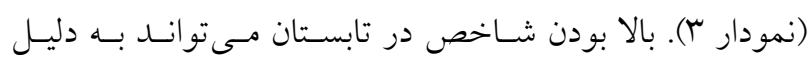

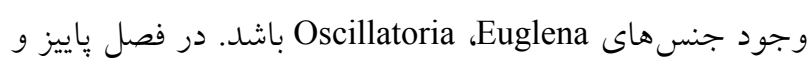
با سرد شدن هوا و كاهش عمق آب وروددى به اين منطقه، عـدد

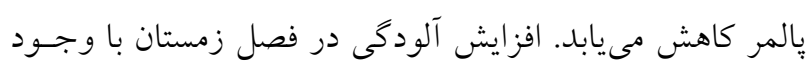

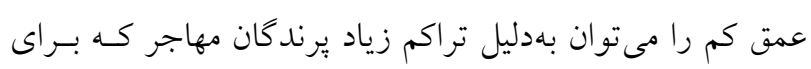

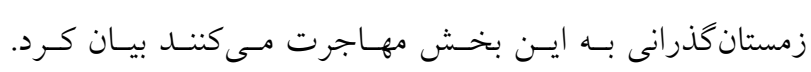

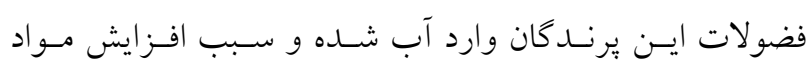

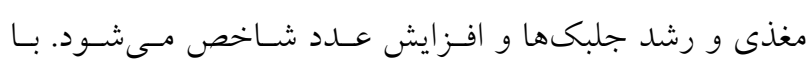

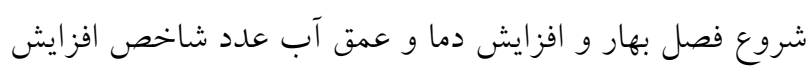

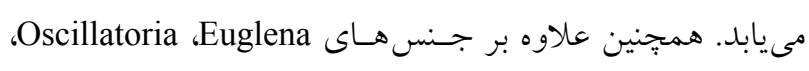
Synedra Melosiera ،Navicula ،Nitzschia نيز در اين منطقـه مشـاهده شـــ كـه سـبب افـزايش

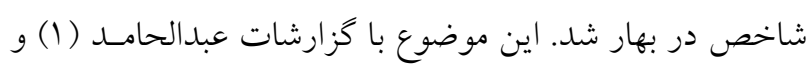
راتناساباباتى (آش) مطابقت دارد.

\section{كل خليج گر گان}

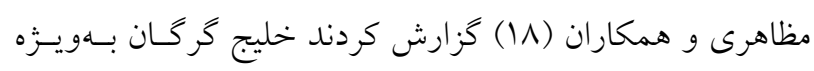

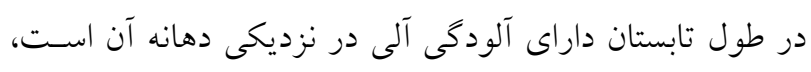

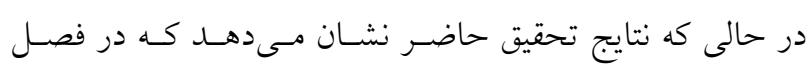

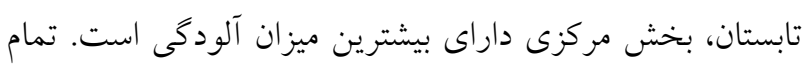
بخش هاى خليج از نظر شاخص بالمر داراى آلودكى آلى بسئيار

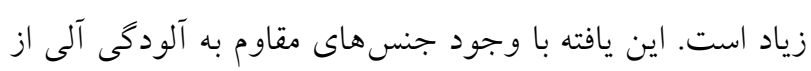

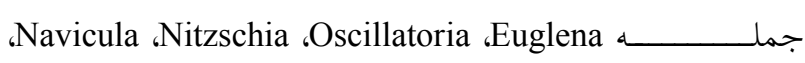
Melosiera

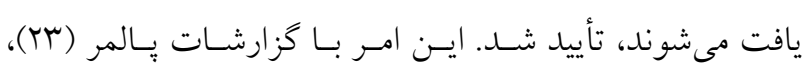

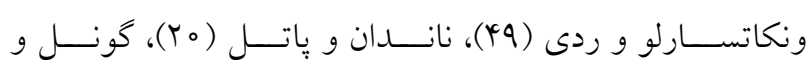

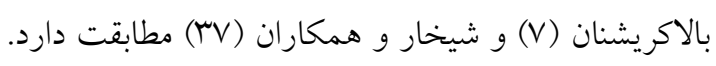

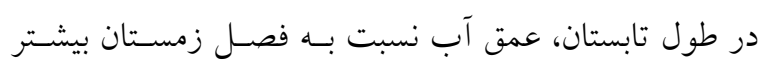
است كه ممكن است بار آلودگى آلى ورودى را تحت تأثير قرار 
مغذى ناشى از باران و رواناب سطحى باشد كه به سمت خلـيج روانه مىشود. نتايج جلبكى نشان مىدهد كه كيفيـت آب خلـيج به يكى سطح آستانه رسيده و بنـابراين، بـراى حفـظ آن نيـاز بــه اقدامات اصلاحى است. براى حفاظت و مديريت، ابتدا بايـــ بـر جلو گيرى كلى از ورود مــواد مغـــى خـارجى بـه درون خلـيج

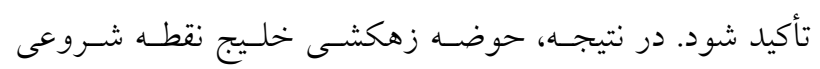
منطقى بــراى برنامسهريـزى و اقـدامات مـديريتى اسـت. كنتـرل فرايندهاى بـومشـناختى داخلـى از طريـق فنـاورىهـاى نـوين زيستمحيطى و يا سـاير معيارهـاى درمـانى، بــراى بـالا رفـتن كيفيت آب مورد نيـاز اسـت. تعيسين معيارهـا و استانداردهايى

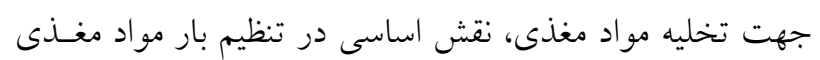
موجود در خليج گر گان خواهد داشت.

\section{تشكر و قدردانى}

نخارند گان از صندوق حمايت از يزٔوهشخران و فنـاوران كشـور بهخاطر تأمين مالى، از شركت مادر تخصصى ماهيـان خاويـارى

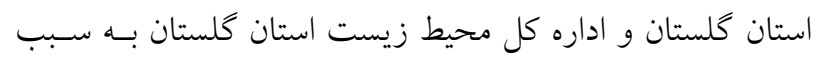
تأمين تجهيزات و ادوات نمونهبـردارى و از مؤسسـهـ تحقيقـات بين المللى تاسماهيان درياى خزر و خـانم دكتـر مـريم فلاحسى بابست كمـك در شناسـايى نمونسههـا تقـــير و تشـكر بـهمــل

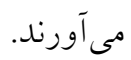

يالانكتونهاى مفيد در طول دوره رشد ماهى براى نيل بــه توليـــ مناسب در استخر ضرورى است. به اين دليل با كوددهى آلى در

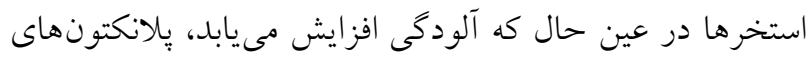
مفيد نيز افزايش يافته و سبب رشد ماهى مىشود (Y\&). مقايسـه شاخص پالمر و فيتو يلانكتونهاى مفيد نشان مىدهد درجايى كه شاخص بيانگر آلودگى است حضـور فيتوبلانكتـونهـاى مفيــ بيشتر است. همدجنين برخى از بِانكتونهاى مشاهده شده مانتـد Synedra ،Chlorella فلزات سنخين از آب و رسوب دارند (TV). با توجه بـه حضـور اين جنس هاى فيتويلانكتونى در خليج گر گان، مىتوان بيشبينى كرد كه اين جنسها سبب جداسازى عناصر سنخين از رسـوبات و آب گردند و بنابراين بررسى دقيـق تـر موضـوع از ايسن جنبـهـ حائز اهميت است.

\section{نتيجه گيرى}

بهطور كلى از يافتههاى شاخص بِالمر مىتوان نتيجه گرفـت كـه.

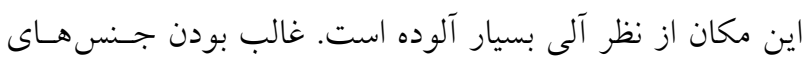

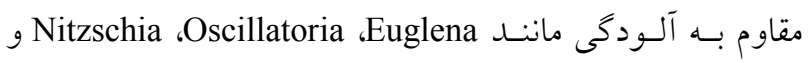
Navicula بهنوان يوتروفيك، حمايت مى كند. عدد بالاى شاخص ممكـن

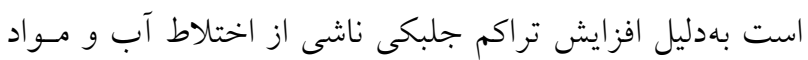

\section{منابع مورد استفاده}

1. Abdel Hamed, M. S. 2007. Effect of algal density in bead, bead size and bead concentrations on wastewater nutrient removal. African Journal of Biotechnology 6: 1185-1191.

2. Barbour, M. T., J. Gerritsen, B. D. Snyder and J. B. Stribling. 1999. Rapid bioassessment protocols for use in streams and wadeable rivers: Periphyton, benthic macroinvertebrates and fish, Second Edition. U.S. Environmental Protection Agency, Washington D.C.

3. Bellinger, E. and D. Sigee. 2010. Algae as bioindicators. pp. 99-136, In: E. Bellinger and D. Sigee (eds.), Freshwater algae: identification and use as bioindicators. John Wiley \& Sons, Chichester.

4. Carpenter, S. R., N. F. Caraco, D. L. Correll, R. W. Howarth, A. N. Sharpley and V. H. Smith. 1998. Nonpoint pollution of surface waters with phosphorus and nitrogen. Ecological Appllications 8: 559-568.

5. Coste, M., C. Bosca and A. Dauta. 1991. Use of algae for monitoring rivers in France. pp. 75-88, In: B. A. Whiton, E. Rott and G. Friedrich (eds.), Use of algae for monitoring rivers. Düsseldorf, E. Rott, Innsbruck.

6. Dwivedi, B. K. and G. C. Pandey. 2002. Physico-chemical factors and algal diversity of two ponds (Girija Kund and Maqubara Pond), Faizabad. Indian Polls Result 21(3): 361-369.

7. Gunale, V. R. and M. S. Balakrishnan. 1981. Biomonitoring of eutrophication in the Pavana, Mula and Mutha rivers through Poona. Indian journal of environmental health 23(4): 316-322. 
8. Harkins, R. D. 1974. An objective Water Quality Index. Journal of the Water Pollution Control Federation 8: 4658.

9. Horner, R. A. 2002. A taxonomic guide to some common marine phytoplankton. Biopress Ltd., Bristol.

10. Hosmani, S. P. and S. G. Bharati. 1980. Algae as indicators of organic pollution. Phykos 19(1): 23-26.

11. Jafari, N. G. and V. R. Gunale. 2006. Hydrobiological study of algae of an urban freshwater river. Journal of Applied Sciences and Environmental Management 10(2):153-158.

12. Jose. L. and C. Kumar. 2011. Evaluation of pollution by Palmer's algal pollution index and physico-chemical analysis of water in four temple ponds of Mattancherry, Ernakulam, Kerala. Nature Environment and Pollution Technology 10(3): 471-472.

13. Joubert, G. 1980. A bioassay application for quantitative toxicity management using the green algae, Selenastrum Capricornutum. Water Research 14: 1759-1763.

14. Karbassi, A. R. and R. Amirnezhad. 2004. Geochemistry of heavy metals and sedimentation rate in a bay adjacent to the Caspian Sea. International Journal of Environmental Science \& Technology 1(3): 191-198. (in Persian).

15. Khalifeh-Nilsaz, M. and F. Kian-Ersi. 2013. Assessment of phytoplankton in agricultural sewage as a feasibility index of aquaculture in Karoon River (Ahwaz to Khorramshahr). Iranian Scientific Fisheries Journal 2(22): 55-64. (in Persian).

16. Lobban, C. S., D. J. Chapman, and B. P. Kremer. 1988. Experimental phycology: A laboratory manual. Press Syndicate: Cambridge University Press, New York.

17. Lohmann, H. 1911. Über das nannoplankton und die Zentrifugie rung kleinster Wasserproben zur Ge winnung desselben in leben-dem Zustande. Internationale Revue der gesamten Hydrobiologie und Hydrographie 4: 1-38.

18. Mazaheri-Kouhanestani, Z., D .L. Roelke, R .Ghorbani and M. Fujiwara. 2019. Assessment of spatiotemporal phytoplankton composition in relation to environmental conditions of Gorgan Bay, Iran. Estuaries and Coasts 42: 173-189.

19. McGeoch, M. A. 1998. The selection, testing and application of terrestrial insects as bioindicators. Biological Reviews 73: 181-201.

20. Nandan, S. N. and R. J. Patel. 1985. Eutrophication in Vishwamitri river flowing through Baroda city. Geobios 2: 60-62.

21. Noel, S. D. and M. R. Rajan. 2015. Evaluation of organic pollution by Palmer's algal genus index and physicochemical analysis of Vaigai River at Madurai. India Natural Resources 3: 7-10.

22. Nybakken, J. W. 1993. Marine biology and ecological approch. Harper Collins College Publishers, California.

23. Palmer, C. M. 1969. A composite rating of algae tolerating organic pollution. Journal of Phycology 5: 78-82.

24. Patrick, R. 1965. Algae as indicator of pollution. In: $3^{\text {rd }}$ Seminar on Biological Problems in Water Pollution. Cincinnati, USA. pp. 223-232.

25. Pearsall, W. H. 1932. Phytoplankton in the English lakes II. Ecology 22: 241-262.

26. Ponce-Palafox. J. T., J. L. Arredondo-Figueroa, S. G. Castillo-Vargasmachuca, G. Rodriguez Chavez Benitez, A. Valle, M. A. RegaladodeDios, F. Medina Carrillo, R. Navarro Villalobos, J. A. Gomez Gurrola and P. Lopez Lugo. 2010. The effect of chemical and organic fertilization phytoplankton and fish production in carp (Cyprinidae) polyculture system. Revista Biociencias Julio 1: 44-50.

27. Pradhan A., P. Bhaumik, S. Das, M. Mishra, S. Khanam, B. Amin Hoque, I. Mukherjee Ranjan, A. Thakur and S. Ray Chaudhuri. 2008. Phytoplankton diversity as indicator of water quality for fish cultivation. American Journal of Environmental Sciences 4: 406-411.

28. Proshkina-Lavrenko, A. E. and E. V. Makarova. 1968. Vodorosli planktona Kaspiyskogo morya (Plankton algae of the Caspian Sea.). Nauka Press, Leningrad. (in Russian).

29. Rai, L. C. and H. D. Kumar. 1976. Systematic and ecological studies on algae of some habitats near Sahupuri, Varanasi. Nova Hedwigia 27: 803-812.

30. Rajmohan. N. and L. Elango. 2005. Nutrient chemistry of groundwater in an intensively irrigated region of southern India, Environmental Geology 47: 820-830.

31. Ratnasabapathy, M. 1975. Biological aspects of Wardieburn sewage oxidation pond. Malaysian Science 3(a): 75-87.

32. Robert, D. S., W. H. Robert and L. G. Everett. 1974. Phytoplankton distribution and water quality indices for Lake Mead (Colorado River). The Journal of Phycology 10: 323-331.

33. Saha. S. B., S. B. Bhattacharya and A. Choudhury. 2000. Diversity of phytoplankton of sewage pollution brackish water tidal ecosystems. Journal of Environmental Biology 21: 9-14.

34. Salem, Z., M. Ghobara and A. A. ElNahrawy. 2017. Spatio-temporal evaluation of the surface water quality in the middle Nile Delta using Palmer's algal pollution index. Egyptian Journal of Basic and Applied Sciences 4(3): 219226.

35. Sangeeta. D. and D. Savita. 2011. Hydro-chemical changes in two eutrophic lakes of Central India after immersion of Durga and Ganesh idol, Research Journal of Chemical Sciences 1(1): 38-45. 
36. Sharbaty, S., M. R. Imanpour, S. Gorgin and S. Hosseini. 2010. The first phase of simulation studies of short-term sea currents in the Gorgan Bay, Research Report. Gorgan University of Agricultural Sciences and Natural Resources, Gorgan. (In Persian)

37. Shekhar, S., B. R. Kiran, E. T. Puttaiah, Y. Shivaraj and K. M. Mahadevan. 2008. Phytoplankton as index of water quality with reference to industrial pollution. Journal of Environmental Biology 29(2): 233-236.

38. Singh, K. P., A. Malik, D. Mohan and S. Sinha. 2004. Multivariate statistical techniques for the evaluation of spatial and temporal variations in water quality of Gomti River (India): a case study. Water Research 38: 3980-3992.

39. Smith V. H., G. D. Tilman and J. C. Nekola. 1999. Eutrophication: impacts of excess nutrient inputs on freshwater, marine and terrestrial ecosystems. Environment Pollution 100:179-196.

40. Sonneman, J. A., P. F. Walsh Breen and S. K. Sharpe. 2001. Effects of urbanization on streams of the Melbourne region, Victoria, Australia. II. Benthic diatom communities. Freshwater Biology 46(4): 553-565.

41. Sudhaker, G., B. Joyothi and V. Venkateswarlu. 1994. Role of diatom as indicator of polluted gradients. Environmental Monitoring and Assessment 33: 85-99.

42. Sullivan, M. J. 2000. Applied diatom studies in estuaries and shallow coastal environments. pp. 334-351, In: E. F. Stoermer and J. P. Smol (eds.), The diatoms: applications for the environmental and earth sciences. Cambridge University Press, Cambridge.

43. Tahami, F. S., A. K. Sany and A. Ganjian. 2017. Water quality study behind Sanandaj Azad Dam using algal bioassay. Journal of Aquatic Ecology 1: 23-32. (in Persian).

44. Taylor, S. L., S. C. Roberts, C. J. Walsh and B. E. Hatt. 2004. Catchment urbanization and increased benthic algal biomass in streams: linking mechanisms to management. Freshwater Biology 49: 835-851.

45. Tomas, C. R. 1997. Identifying marine phytoplankton. Academic Press, SanDiego.

46. Trivedy, R. K. 1986. Role of algae in biomonitoring of water pollution. Asian Environment 8(3): 31-42.

47. Upadhyay, R., A. Pandey, S. K. Upadhyay and A. Bajpai. 2012. Annual sedimentation yield and sediment characteristics of Upper Lake, Bhopal. Research Journal of Chemical Sciences 2(2): 65-74.

48. Vega M., R. Pardo, E. Barrado and L. Deban. 1998. Assessment of seasonal and polluting effects on the quality of river water by exploratory data analysis. Water Research 32: 3581-3592.

49. Venkateswarlu, V. and M. P. Reddy. 1985. Algae as biomonitor in river ecology. In: Proceeding of Biomonitoring State Environment Symposium, Indian National Science Academy. New Delhi, India. pp. 183-189.

50. Walsh, C. J. 2000. Urban impacts on the ecology of receiving waters: a framework for assessment, conservation and restoration. Hydrobiologia 431(2): 107-114. 


\title{
Ecological Assessment of Organic Pollution in the Gorgan Bay, Using Palmer Algal Index
}

\author{
P. Maleki ${ }^{1}$, R. Patimar ${ }^{1 *}$, H. Jafarian ${ }^{1}$, A. R. Mahini², R. Ghorbani ${ }^{3}$, \\ M. Gholi zade ${ }^{1}$ and M. Harsij ${ }^{1}$
}

(Received: February 02-2020; Accepted: June 08-2020)

\begin{abstract}
The problem of pollution in the Caspian sea has attracted increasing scientific concerns in recent years, but still, there is limited data relevant to the Gorgan bay. The current study aimed to evaluate the organic pollution of the Gorgan Bay, using Palmer Algal Index. Sampling was conducted seasonally in triplicate from summer 2017 to spring 2018. Phytoplankton samples were collected from surface water (maximum depth of $50 \mathrm{~cm}$ ), using a one-liter sampling bottle and fixed in $2.5 \%$ formaldehyde buffer solution. A total of 23 stations were selected including, seven stations in the eastern areas, eight stations in the centre, and eight stations in the western part of the bay. The Palmer Index indicated that all parts of the bay are highly polluted, in the four seasons. Comparison of the index among the three parts of the bay indicated that the central areas are more polluted than other areas in the three seasons, from summer to winter, while only in the spring, the western area of the bay showed the highest value of the index. The predominance of the pollution resistant Phyto-genera such as Oscillatoria, Euglena, Cyclotella, Navicula, Nitzschia, and Synedra supports the classification of the bay as eutrophic. Generally, the results of the algal index revealed that the water quality of the bay has reached a critical level.
\end{abstract}

Keywords: Phytoplankton, Palmer Index, Gorgan Bay, Organic Pollution

1. Department of Fisheries, Faculty of Agriculture and Natural Resources, Gonbad Kavous University, Gonbad Kavous, Iran.

2. Department of Environment, Faculty of Fisheries and Environment, Gorgan University of Agricultural Sciences and Natural Resources, Gorgan, Iran.

3. Department of Fisheries, Faculty of Fisheries and Environment, Gorgan University of Agricultural Sciences and Natural Resources, Gorgan, Iran.

*: Corresponding Author, Email: rpatimar@gmail.com 